\title{
Use of Experimental Design to Evaluate the Effect of the Incorporation of Quartzite Residues in Ceramic Mass for Porcelain Tile Production
}

\author{
Karina Ruiz Silva ${ }^{a}{ }^{\circledR}$, Liszandra Fernanda Araújo Campos ${ }^{b}$, Lisiane Navarro de Lima Santana ${ }^{a}$ \\ ${ }^{a}$ Unidade Acadêmica de Engenharia de Materiais, Universidade Federal de Campina Grande - UFCG, \\ 58429-900, Campina Grande, PB, Brasil \\ ${ }^{b}$ Departamento de Engenharia de Materiais, Universidade Federal da Paraiba - UFPB, 58051-900, \\ João Pessoa, PB, Brasil
}

Received: May 31, 2018; Revised: September 13, 2018; Accepted: October 08, 2018

\begin{abstract}
The potential of using quartzite residues in the composition of an industrial ceramic mass for porcelain tile production was investigated through experimental design. Chemical, physical and microstructural analyses were accomplished to understand how the incorporation of quartzite residues affects the material, before and after sintering. Central composite design was used to analyze the effects of firing temperature $\left(1143 ; 1160 ; 1200 ; 1240 ; 1257^{\circ} \mathrm{C}\right)$ and residue content $(1.76 ; 3 ; 6 ; 9 ; 10.24 \mathrm{wt} . \%)$ on the physical-mechanical properties of the material, and regression models correlating these factors to the response variables linear shrinkage, water absorption, apparent density and flexural strength were adjusted. Firing temperature had statistically significant effect on the response variables, so that the elevation of its levels contributed to the properties improvement. Residue content presented nonsignificant effect. In conclusion, specimens containing quartzite residues, up to $10.24 \mathrm{wt} . \%$, sintered at 1240 and $1257^{\circ} \mathrm{C}$, fulfil the ISO 13006 requirements for porcelain tiles.
\end{abstract}

Keywords: Ceramics, porcelain tile, quartzite residue, central composite design.

\section{Introduction}

The ornamental rock industry is based mainly on the extraction, cutting and polishing of rocks as granite, marble, slate, gneiss, quartzite and others. This type of industry produces large amounts of mineral wastes worldwide, which are usually disposed in landfills or discarded directly into the environment without previous treatment ${ }^{1-3}$.

The inadequate disposal of rock residues puts serious environmental and health concerns, creating necrotic conditions for flora and fauna while, after drying, fine particles can be deposited in the lungs of mammals via breath ${ }^{3}$.

Considering that some natural raw materials used in traditional ceramic industry derive from the decomposition of rocks, a similar mineralogical composition between them and rock wastes should be expected. It means that residues from ornamental rock extractive activity are good substitutes for high added-value raw materials used in the production of traditional ceramics ${ }^{3,4}$. The use of mineral wastes, after detection of their potentialities, contributes to the diversification of products and reduction of manufacturing costs, besides representing the conservation of non-renewable resources, energy saving and improvement in population health ${ }^{4,5}$.

Quartzite is geologically classified as a metamorphic rock, composed almost entirely of quartz grains. The techniques used in the extraction and processing of quartzite result in high generation of coarse and fine residues, which are nontoxic and non-hazardous, but are classified as non-inert.

*e-mail: karinaruizsilva@gmail.com
Chemically, it is composed mostly of silicon oxide $\left(\mathrm{SiO}_{2}\right)$, but also of aluminum oxide $\left(\mathrm{Al}_{2} \mathrm{O}_{3}\right)$, calcium oxide $(\mathrm{CaO})$ and alkaline oxides $\left(\mathrm{K}_{2} \mathrm{O} \text { and } \mathrm{Na}_{2} \mathrm{O}\right)^{3,6}$.

In recent years, the use of quartzite residues as an alternative raw material in the production of ceramic products has been investigated. Carreiro et al. ${ }^{6}$ demonstrated the feasibility of incorporating quartzite residue in a mass that is used in the manufacture of structural ceramic products. Studies performed by Medeiros et al. ${ }^{7}$ showed that the quartzite residue can be considered as an alternative raw material for use in sanitary ware industry. Barros et al. ${ }^{8}$ demonstrated the technical viability of the use of quartzite residues as raw materials in mortar. Torres et al. ${ }^{3}$ showed that the incorporation of quartzite residue as a main component in red-clay-based stoneware tiles allows to obtain semi-porous ceramic bodies. However, the introduction of this type of residue in compositions used to produce porcelain tiles need to be further analyzed.

One way of analyzing the effects of introducing quartzite residues into ceramic masses is through statistical design of experiments, which has many advantages over classical methods where one parameter is optimized at each time ${ }^{9}$. In statistical designs, all experiments are carried out in a planned way and the results can be evaluated systematically by means of the variance analysis ${ }^{10}$. The central composite design comprise of integrated factorial design, group of star points for the estimation of curvature, and center points for the determination of experimental reproducibility ${ }^{11}$. The difference in relation to the other factorial design methods is the usage of axial points defined as $\alpha$ values $^{12}$. This tool is widely used to establish a second-order response surface 
model in process optimization studies ${ }^{13}$, and enables to gather more data with lower number of experiments ${ }^{14}$.

The main objective of this work was to apply the experimental design, more specifically the central composite design, to evaluate the effect of the incorporation of quartzite residues in a ceramic mass for porcelain tile production. Using this tool, it was studied how the factors - firing temperature and residue content - influence the physical-mechanical properties of the material, and it was adjusted regression models correlating these factors to the response variables linear shrinkage, water absorption, apparent density and flexural strength.

\section{Experimental Procedures}

The raw materials used in this study were: an industrial ceramic mass for porcelain tile production and quartzite residues of fine and coarse particles. The mass was supplied by a ceramic tiles company, and residues were supplied by a quartzite processing unit, both located in the State of Paraiba, Brazil.

In order to evaluate the effect of firing temperature (FT) and residue content (RC) on the physical-mechanical properties of the material, it was used factorial design $2^{2}$ with 4 axial points and 2 experiments at the central point (central composite design). Table 1 presents the factors, their levels and coded values.

The design of experiments was performed twice. At the first time, it was studied the incorporation of fine quartzite residue in the ceramic mass for porcelain tile production. At the second time, it was analyzed the incorporation of coarse quartzite residue, after milling process.

Initially, the coarse quartzite residue was ground in a ball mill to reduce its particles size. All the raw materials were sieved through an ABNT No. 200 sieve (0.075 mm) and then subjected to chemical characterization by X-ray fluorescence (XRF), using a Shimadzu EDX-720 energy dispersive X-ray fluorescence spectrometer.

In order to verify the changes in the mineralogical, physical and thermal profiles of the porcelain ceramic mass, caused by the incorporation of quartzite, the pure mass and selected mixtures containing up to $10.24 \mathrm{wt} . \%$ of fine residue and milled coarse residue were characterized by the following techniques: X-ray diffraction (XRD), using a Shimadzu Lab XRD-6000 X-ray diffractometer equipped with a $\mathrm{CuK} \alpha$ radiation tube, operating at a $2 \theta$ scan angle of $5-40^{\circ}$, scan speed of $2^{\circ} / \mathrm{min}$ and step size of $0,02^{\circ}$; particle size analysis (PSA), using a Cilas 1064-LD particle size analyzer; differential thermal analysis (DTA) and thermogravimetric analysis (TGA), using a TA Instruments SDT thermal analyzer, at a maximum temperature of $1270^{\circ} \mathrm{C}$ and heating rate of $12.5^{\circ} \mathrm{C} / \mathrm{min}$.

After complete homogenization via dry process, the mixtures had the adjust of their moisture contents $(\sim 6 \%)$, and then were passed through an ABNT No. 40 sieve $(0.425 \mathrm{~mm})$ and remained at rest for 24 hours. The porcelain formulations were pressed into rectangular test specimens (approximate dimensions of $20 \mathrm{~mm} \times 7 \mathrm{~mm} \times 60 \mathrm{~mm}$ ), under a pressure of $50 \mathrm{MPa}$, using a Marcon MPH-30 uniaxial hydraulic press. The resulting test specimens were oven-dried at $110^{\circ} \mathrm{C}$ for 24 hours and then heat-treated in an INTI electric furnace, equipped with a Flyever FE50RPN temperature controller (accuracy of $\pm 2^{\circ} \mathrm{C}$ ), applying a heating rate of $49^{\circ} \mathrm{C} / \mathrm{min}$ and a 2-min hold time at the maximum firing temperature. The cooling rate was $50^{\circ} \mathrm{C} / \mathrm{min}$. Chosen parameters for laboratory-scale firing cycle were adapted from parameters used in industry.

The following physical-mecanical properties were evaluated: linear shrinkage, water absorption, apparent density and mechanical strength. Linear shrinkage values were determined from the linear dimensional variation of sintered specimens. Water absorption and apparent density values were determined according to the Archimedes method, using water at room temperature as immersion fluid. Lastly, 3-point flexural strength tests were performed using a Shimadzu AG-X universal test machine, equipped with a Shimadzu load cell, type SPL - $10 \mathrm{kN}$, with a capacity of $10 \mathrm{kN}$, operating at $0.5 \mathrm{~mm} / \mathrm{min}$ speed of applied force.

The crystalline phases of selected fired samples were analyzed by XRD technique and identified using the Untitled XRD search/match tool for Qualitative Analysis, and the JCPDS powder diffraction files contained in the PCPDFWIN database of the Shimadzu XRD-6000 software. The fracture surfaces of the same samples was morphologically characterized by scanning electron microscopy (SEM) using a Shimadzu SSX microscope, in the secondary electrons mode.

\section{Results and Discussion}

Table 2 describes the chemical composition of the raw materials: ceramic mass for porcelain tile production (PO), fine quartzite residue (FR) and milled coarse quartzite residue (MCR). The ceramic mass is composed mostly of silica $\left(\mathrm{SiO}_{2}\right)$ and alumina $\left(\mathrm{Al}_{2} \mathrm{O}_{3}\right)$, which together correspond

Table 1. Analyzed factors (FT - Firing temperature; RC - Residue content), their levels and coded values.

\begin{tabular}{lccccc}
\multicolumn{1}{c}{ LEVELS } & $-\sqrt{2}$ & -1 & 0 & +1 & $+\sqrt{2}$ \\
\hline FACTORS & & & & & \\
\hline FT $\left({ }^{\circ} \mathrm{C}\right)$ & 1143 & 1160 & 1200 & 1240 & 1257 \\
RC $(\%)$ & 1.76 & 3.00 & 6.00 & 9.00 & 10.24 \\
\hline
\end{tabular}


Table 2. Chemical composition of the raw materials (\%): Ceramic mass for porcelain tile (PO); Fine quartzite residue (FR); Milled coarse quartzite residue (MCR).

\begin{tabular}{lccccccccccc}
\hline & $\mathrm{SiO}_{2}$ & $\mathrm{Al}_{2} \mathrm{O}_{3}$ & $\mathrm{~K}_{2} \mathrm{O}$ & $\mathrm{CaO}$ & $\mathrm{MgO}$ & $\mathrm{Fe}_{2} \mathrm{O}_{3}$ & $\mathrm{SO}_{3}$ & $\mathrm{BaO}$ & $\mathrm{TiO}_{2}$ & $\mathrm{Na}_{2} \mathrm{O}$ & $\mathrm{Others}$ \\
\hline $\mathrm{PO}$ & 67.75 & 23.82 & 3.28 & 1.48 & 1.08 & 0.62 & 0.17 & - & - & 1.35 & 0.45 \\
$\mathrm{FR}$ & 80.28 & 11.82 & 4.55 & 0.35 & 0.96 & 1.09 & 0.56 & 0.27 & 0.10 & - & 0.02 \\
$\mathrm{MCR}$ & 67.71 & 18.50 & 7.80 & 1.23 & 1.78 & 1.96 & 0.35 & 0.39 & 0.22 & - & 0.06 \\
\hline
\end{tabular}

to approximately $91.57 \%$, but also presents a significant amount of fluxing oxides $\left(\mathrm{K}_{2} \mathrm{O}, \mathrm{Na}_{2} \mathrm{O}\right)$ and auxiliary fluxing oxides $\left(\mathrm{CaO}, \mathrm{MgO}, \mathrm{Fe}_{2} \mathrm{O}_{3}\right)$. Silica is commonly found in several mineralogical clayey and non-clayey phases, such as kaolinite, mica, feldspar and quartz, which corresponds to its purest natural form. Alumina is also usually associated with some of these mineralogical phases ${ }^{6}$. Potassium $\left(\mathrm{K}_{2} \mathrm{O}\right)$ and sodium $\left(\mathrm{Na}_{2} \mathrm{O}\right)$ oxides generally come from feldspars and micas, while calcium $(\mathrm{CaO})$ and magnesium $(\mathrm{MgO})$ oxides may be associated with minerals such as dolomite. The small content found for iron oxide $\left(\mathrm{Fe}_{2} \mathrm{O}_{3}\right)$ is an essential factor for the production of white ceramics, since it can develop a reddish colour in products during sintering ${ }^{15}$. The chemical composition of the quartzite residues, FR and MCR, indicates that silica is the predominant oxide in both, followed by alumina. The high $\mathrm{SiO}_{2}$ and $\mathrm{Al}_{2} \mathrm{O}_{3}$ contents $\left(80.28 \% \mathrm{SiO}_{2}\right.$ and $11.82 \% \mathrm{Al}_{2} \mathrm{O}_{3}$ for FR; $67.71 \% \mathrm{SiO}_{2}$ and $18.50 \% \mathrm{Al}_{2} \mathrm{O}_{3}$ for MCR) are typical of ornamental metamorphic rocks ${ }^{16}$. In smaller proportions, there are fluxing oxides, normally present in quartzite residues as impurities in the form of feldspar and micaceous mineral ${ }^{16}$. Both residues come from the sawing of the quartzite blocks. However, the difference in their chemical compositions, mainly for $\mathrm{SiO}_{2}$ contents, is probably related to the sieving process that occurred during the preparation of the raw materials. The entire fine fraction passed through the 200 mesh sieve. On the other hand, the coarse fraction, even after being subjected to the milling process, did not completely pass through the 200 mesh sieve, so that the harder and coarser particles were retained. Other researchers who studied the incorporation of different types of ornamental rock residues into ceramic masses detected silica and alumina contents similar to those found in this work ${ }^{3,6,16,17}$.

Fig. 1 shows the XRD spectra of the porcelain ceramic mass and compositions with 10.24 wt.\% of the quartzite residues, FR and MCR. These compositions were selected since they present the highest residue content studied in this work. For the pure ceramic mass, it is verified the presence of the following mineralogical phases: kaolinite (JCPDS: 89-6538), dolomite (JCPDS: 89-5862), feldspar (JCPDS: 89-8574), mica (JCPDS: 83-1808) and quartz (JCPDS: 46-1045). For compositions containing quartzite residues, these same crystalline phases are observed, in addition to the microcline (JCPDS: 19-0932), which is a potassic feldspar. It can also be seen that the incorporation of both residues, up to $10.24 \mathrm{wt} . \%$, caused an increase in the intensity of the quartz peaks, mainly for the composition with fine residue. For the other crystalline phases, only small differences in intensity of the diffraction peaks are observed.

Table 3 shows the particle size distribution of the porcelain ceramic mass and compositions with fine quartzite residue (PFR) and milled coarse quartzite residue (PMCR). For each composition, it is presented the average diameter (AD) and the volumetric fraction for diameters (D) below $2 \mu \mathrm{m}$, between 2 and $20 \mu \mathrm{m}$ and above $20 \mu \mathrm{m}$. The clay fraction $(\mathrm{D}<2 \mu \mathrm{m})$ present in the porcelain ceramic mass is $23.06 \%$, while the silt $(2 \mu \mathrm{m}<\mathrm{D}<20 \mu \mathrm{m})$ and sand (D $>20 \mu \mathrm{m})$ fractions correspond respectively to 59.61 and $17.33 \%$. For all studied compositions, it is observed that clay fractions are similar to each other and quite close to the value found for the pure ceramic mass. However, the introduction of residues in the mass caused a decrease in the values of the silt fraction (ranging from 55.06 to $57.37 \%$ for compositions with fine residue; and from 54.80 to $55.19 \%$ for compositions with milled coarse residue) and increase in the values of the sand fraction (ranging from 18.42 to $21.09 \%$ for compositions with fine residue; and from 21.69 to $23.38 \%$ for compositions with milled coarse residue). The correlation between $\mathrm{AD}$ values of the porcelain ceramic mass and of the other compositions reveals that the incorporation of fine residue contributed to an average increase of approximately $7.00 \%$ in the mass AD, whereas the incorporation of milled coarse residue caused a much more significant average elevation on it, which was approximately $19.20 \%$.

Fig. 2 shows the thermal analysis (TGA - thermogravimetric analysis and DTA - differential thermal analysis) of the porcelain ceramic mass and compositions with $10.24 \mathrm{wt} . \%$ of the quartzite residues, FR and MCR. These compositions were chosen since they present the highest residue content studied in this work. The DTA curve of the ceramic mass presents four endothermic peaks and two discrete exothermic peaks. The first endothermic peak occurs at $\sim 50^{\circ} \mathrm{C}$ and corresponds to the release of the free and adsorbed water, resulting in a mass loss of approximately 1.08 wt.\%. The second occurs at $\sim 512^{\circ} \mathrm{C}$ and is attributed to the dehydroxylation of clay minerals present in the sample, such as kaolinite, resulting in a mass loss of approximately $4.73 \mathrm{wt} \%$. The removal of the structural hydroxyls from kaolinite occurs through reorganization of its octahedral layer in a tetrahedral configuration, giving rise to metakaolinite ${ }^{18}$. Other researchers observed the same event at $\sim 448.8^{\circ} \mathrm{C}^{19}, \sim 520^{\circ} \mathrm{C}^{3}, \sim 528.7^{\circ} \mathrm{C}^{20}$, and at $\sim 553^{\circ} \mathrm{C}^{18}$. The small endothermic peak at $\sim 576^{\circ} \mathrm{C}$ 
is attributed to the polymorphic transformation of $\alpha-\beta$ quart $z^{19,20}$. The fourth and last endothermic peak, at $\sim 670^{\circ} \mathrm{C}$, is ascribed to a rapid transition reaction probably triggered by the onset of clay sintering and changes in the crystalline structure $^{21}$. The two discrete exothermic peaks, at $\sim 990^{\circ} \mathrm{C}$ and $\sim 1055^{\circ} \mathrm{C}$, are associated with spinel phase formation and mullite nucleation. These results are in agreement with previous studies, which suggest the spinel formation and/or mullite nucleation at $\sim 980^{\circ} \mathrm{C}^{3}, \sim 989.9^{\circ} \mathrm{C}^{19}$ and $\sim 999.6^{\circ} \mathrm{C}^{18}$.

The DTA curve of the composition with $10.24 \mathrm{wt} . \%$ of fine residue follows exactly the same behavior presented by the pure porcelain ceramic mass, exhibiting endothermic

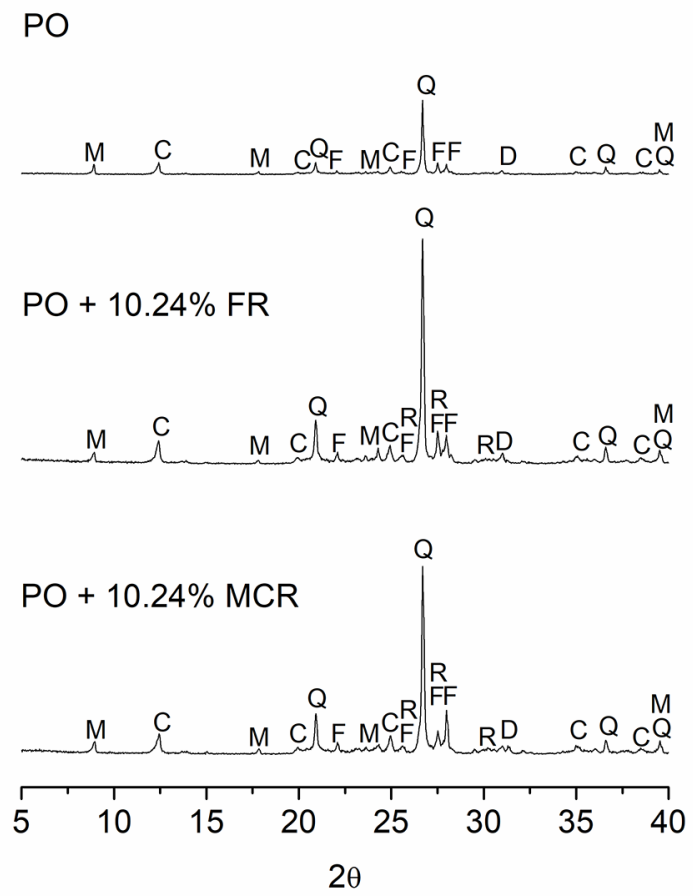

Figure 1. XRD spectra of the porcelain ceramic mass and compositions with 10.24 wt.\% of quartzite residues, FR and MCR. D - Dolomite; F - Feldspar; K - Kaolinite; M - Mica; R - Microcline; Q - Quartz.
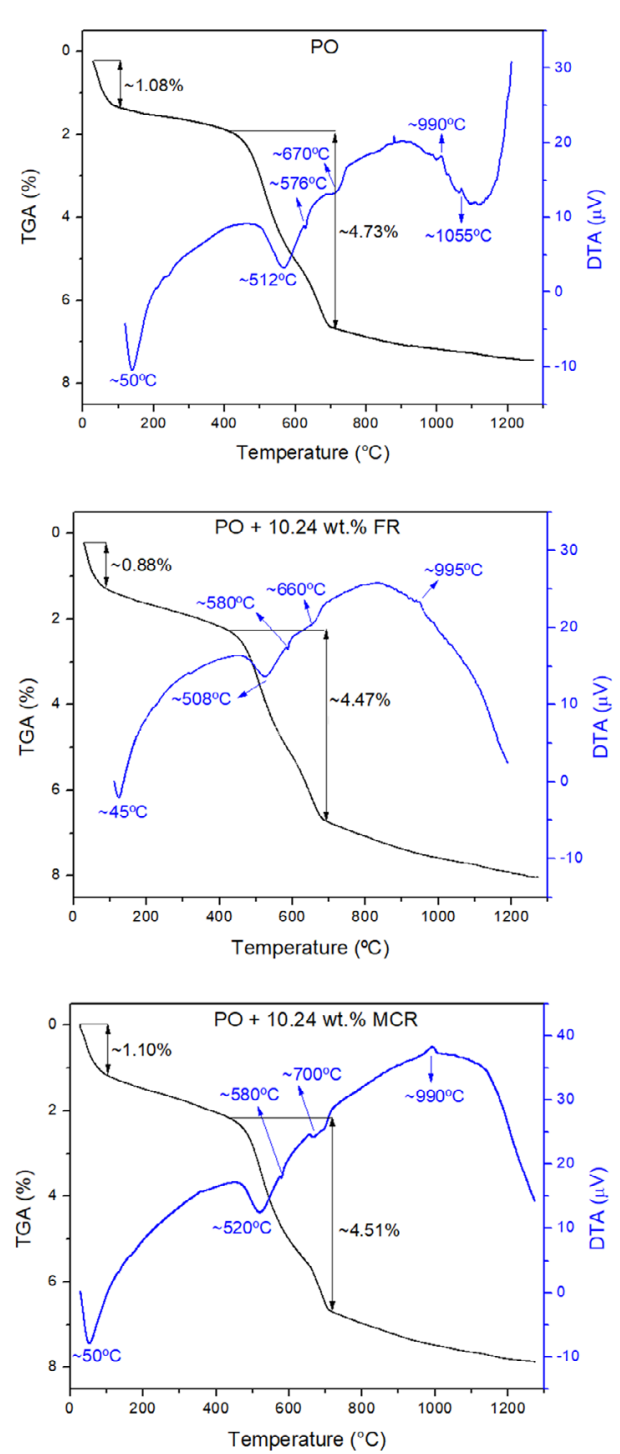

Figure 2. Thermogravimetric analysis (TGA) and differential thermal analysis (DTA) of the porcelain ceramic mass and compositions with 10.24 wt.\% of quartzite residues, FR and MCR.

Table 3. Average diameter (AD) and volumetric fraction for diameters (D) below $2 \mu \mathrm{m}$, between 2 and $20 \mu \mathrm{m}$ and above $20 \mu \mathrm{m}$, for the porcelain ceramic mass (PO) and compositions with fine quartzite residue (PFR) and milled coarse quartzite residue (PMCR).

\begin{tabular}{|c|c|c|c|c|c|}
\hline Composition & $\begin{array}{l}\mathrm{RC} \\
(\%)\end{array}$ & $\begin{array}{c}\mathrm{D}<2 \mu \mathrm{m} \\
(\%)\end{array}$ & $\begin{array}{c}2 \mu \mathrm{m}<\mathrm{D}<20 \mu \mathrm{m} \\
(\%)\end{array}$ & $\begin{array}{c}\mathrm{D}>20 \mu \mathrm{m} \\
(\%)\end{array}$ & $\begin{array}{c}\mathrm{AD} \\
(\mu \mathrm{m})\end{array}$ \\
\hline \multirow[t]{3}{*}{$\mathrm{PO}$} & 0 & 23.06 & 59.61 & 17.33 & 10.56 \\
\hline & 1.76 & 23.85 & 55.06 & 21.09 & 11.91 \\
\hline & 3.00 & 24.69 & 56.65 & 18.66 & 11.14 \\
\hline \multirow[t]{5}{*}{ PFR } & 6.00 & 23.51 & 56.42 & 20.07 & 11.66 \\
\hline & 9.00 & 25.05 & 56.53 & 18.42 & 10.69 \\
\hline & 10.24 & 23.25 & 57.37 & 19.38 & 11.09 \\
\hline & 1.76 & 23.28 & 54.97 & 21.75 & 12.42 \\
\hline & 3.00 & 23.36 & 54.95 & 21.69 & 12.43 \\
\hline \multirow[t]{3}{*}{ PMCR } & 6.00 & 22.92 & 54.80 & 22.28 & 12.63 \\
\hline & 9.00 & 22.94 & 55.19 & 21.87 & 12.46 \\
\hline & 10.24 & 21.47 & 55.15 & 23.38 & 13.00 \\
\hline
\end{tabular}


peaks at temperatures of $\sim 45^{\circ} \mathrm{C}, \sim 508^{\circ} \mathrm{C}, \sim 580^{\circ} \mathrm{C}$ and $\sim 660^{\circ} \mathrm{C}$, and a discrete exothermic peak at $\sim 995^{\circ} \mathrm{C}$. In this case, the release of the free and adsorbed water resulted in a mass loss of approximately $0.88 \mathrm{wt} . \%$ while the dehydroxylation of clay minerals present in the sample resulted in a mass loss of approximately $4.47 \mathrm{wt} . \%$. In relation to the DTA curve of the composition containing $10.24 \mathrm{wt} . \%$ of milled coarse residue, it also follows the same behavior of the pure ceramic mass, presenting endothermic peaks at temperatures of $\sim 50^{\circ} \mathrm{C}, \sim 520^{\circ} \mathrm{C}, \sim 580^{\circ} \mathrm{C}$ and $\sim 700^{\circ} \mathrm{C}$, and a small exothermic peak at $\sim 990^{\circ} \mathrm{C}$. The release of the free and adsorbed water resulted in a mass loss of approximately $1.10 \mathrm{wt} . \%$ and the dehydroxylation of clay minerals, in a mass loss of approximately $4.51 \mathrm{wt} . \%$. These results indicate that the elevation of quartz content in the compositions with quartzite residues caused a slight decrease in the mass loss of them, mainly for PO $+10.24 \mathrm{wt} . \% \mathrm{FR}$, which presented the quartz peaks with greater intensity (Fig. 1). This happens because the elevation in quartz content leads to a proportional decrease in the content of clay minerals.

Table 4 lists the values of the dependent variables: linear shrinkage (LS), water absorption (WA), apparent density (AD) and 3-point flexural strength (FS) of porcelain specimens containing fine quartzite residue (PFR) and milled coarse quartzite residue (PMCR). All of them were prepared according to the experimental planning matrix, obtained with the aid of the software Statistica 7.0.

With the results observed for LS, WA, AD and FS, it was possible to obtain regression equations correlating these dependent variables with the firing temperature (FT) factor. In order to build the mathematical models, only the factors that had statistically significant effects on the studied variables, at the level of $95 \%$ confidence, were considered. Therefore, the residue content $(\mathrm{RC})$ factor was not added in the equations since it did not present statistically significant effects. The mathematical models are presented by Equations (1) to (8).

$$
\begin{aligned}
& L S_{P F R}(\%)=-1064.6263_{( \pm 93.3737)}+1.7253(F T)_{( \pm 0.1557)} \\
& -0.0007(F T)_{( \pm 0.0001)}^{2}
\end{aligned}
$$$$
L S_{P M C R}(\%)=-702.1958_{( \pm 153.5375)}+1.1221(F T)_{( \pm 0.2560)}
$$$$
-0.0004(F T)_{( \pm 0.0001)}^{2}
$$

$$
\begin{aligned}
& W A_{P F R}(\%)=2317.7587_{( \pm 141.6561)}-3.7478(F T)_{( \pm 0.2362)} \\
& +0.0015(F T)_{( \pm 0.0001)}^{2}
\end{aligned}
$$

$$
\begin{aligned}
& W A_{P M C R}(\%)=1691.7703_{( \pm 160.2797)}-2.7060(F T)_{( \pm 0.2673)} \\
& +0.0011(F T)_{( \pm 0.0001)}^{2}
\end{aligned}
$$

$$
\begin{aligned}
& A D_{P F R}\left(\mathrm{~g} / \mathrm{cm}^{3}\right)=-76.8864_{( \pm 6.9570)}+0.1276(F T)_{( \pm 0.0116)} \\
& -0.0001(F T)_{( \pm 0.0000)}^{2}
\end{aligned}
$$

$$
\begin{aligned}
& A D_{P M C R}\left(\mathrm{~g} / \mathrm{cm}^{3}\right)=-52.8866_{( \pm 10.6955)}+0.0878(F T)_{( \pm 0.0178)} \\
& -0.0003(F T)_{( \pm 0.0000)}^{2}
\end{aligned}
$$

$F S_{P F R}(M P a)=-3700.4440_{( \pm 1261.3290)}+5.8330(F T)_{( \pm 2.1035)}$ $-0.0023(F T)_{( \pm 0.0009}^{2}$

$F S_{P M C R}(M P a)=-445.9800_{( \pm 41.1569)}+0.4095(F T)_{( \pm 0.0343)}$

Table 5 shows the main statistical parameters of mathematical models: F-test, p-value and coefficient of determination $\mathrm{R}^{2}$. It is verified that all proposed models have statistical significance, at the $95 \%$ confidence level, since the $\mathrm{p}$-value $<0.05$ and F-test $>$ F-table for each of them ${ }^{22}$. The high values of $\mathrm{R}^{2}$ indicate that the adjusted models do not present considerable variability.

Fig. 3 to 6 show, respectively, the response surfaces of the variables LS, WA, AD and FS, obtained from Equations (1) to (8). Basically, they are the graphical representation of the mathematical models proposed for each of the studied variables.

The linear shrinkage indicates the degree of densification during sintering, and is very important for the dimensional control of the finished ceramic products ${ }^{16}$. In Fig. 3, it can be noticed a progressive increase in the linear shrinkage values as the sintering temperature is increased. For both compositions, PFR and PMCR, it is observed an increase of approximately $6 \%$ in the linear shrinkage values when the firing temperature is elevated from 1143 to $1240^{\circ} \mathrm{C}$. Above $1240^{\circ} \mathrm{C}$, no more changes were observed in the values of the LS variable. During firing, at temperatures of about $900-1000^{\circ} \mathrm{C}$, an important quantity of liquid phase begins to form ${ }^{23}$. As firing temperature rises, especially from $1170^{\circ} \mathrm{C}$, a greater amount of liquid phase is produced and liquid-phase viscosity decreases. This facilitates the elimination of pores, thereby increasing shrinkage ${ }^{24}$.

Water absorption is an important physical property, since it is related to the microstructure of the sintered ceramic matrix and determines the open porosity level of the pieces ${ }^{19}$. In Fig. 4, it is verified that the increase of firing temperature up to $1240^{\circ} \mathrm{C}$ caused a reduction of approximately $12 \%$ in the water absorption for the PFR and PMCR compositions, making its values very close to zero. By the capillary action and surface tension, the glassy phase formed during sintering infiltrates the open pores of the structure and causes densification of the ceramic pieces ${ }^{16}$. According to the international standard ISO $13006^{25}$, porcelain tiles are ceramic tiles with water absorption equal to or less than $0.5 \%$ (WA $\leq$ $0,5 \%)$. Thus, in the present study, compositions with up to 10.24 wt.\% of quartzite residues, FR and MCR, which were sintered at $1240^{\circ} \mathrm{C}$ and $1257^{\circ} \mathrm{C}$, are classified as porcelain tiles. According to the same standard, the compositions sintered at $1200^{\circ} \mathrm{C}$ can be classified as stoneware $(0.5 \%<$ WA $\leq 3.0 \%$ ), those sintered at $1160^{\circ} \mathrm{C}$ can be classified as semi-porous $(6.0 \%<\mathrm{WA} \leq 10,0 \%)$, and those sintered at $1143^{\circ} \mathrm{C}$ as porous ( $\mathrm{AA}>10.0 \%$ ). 
Table 4. Values of linear shrinkage (LS), water absorption (WA), apparent density (AD) and 3-point flexural strength (FS), obtained for compositions with fine quartzite residue (PFR) and compositions with milled coarse quartzite residue (PMCR).

\begin{tabular}{|c|c|c|c|c|c|c|}
\hline \multirow[b]{2}{*}{ Samples } & \multicolumn{2}{|c|}{ Factors } & \multicolumn{4}{|c|}{ Dependent variables } \\
\hline & $\begin{array}{l}\text { FT } \\
\left({ }^{\circ} \mathrm{C}\right)\end{array}$ & $\begin{array}{l}\mathrm{RC} \\
(\%)\end{array}$ & $\begin{array}{l}\text { LS } \\
(\%)\end{array}$ & $\begin{array}{l}\text { WA } \\
(\%)\end{array}$ & $\begin{array}{c}\mathrm{AD} \\
\left(\mathrm{g} / \mathrm{cm}^{3}\right)\end{array}$ & $\begin{array}{c}\mathrm{FS} \\
(\mathrm{MPa})\end{array}$ \\
\hline PFR1 & 1160 & 3.00 & $3.67 ; 3.43 ; 3.83$ & $8.37 ; 9.11 ; 8.52$ & $2.06 ; 2.03 ; 2.05$ & $32.29 ; 32.00$ \\
\hline PFR2 & 1160 & 9.00 & $3.53 ; 3.34 ; 4.29$ & $10.15 ; 10.50 ; 8.43$ & $2.00 ; 1.99 ; 2.05$ & $29.03 ; 29.40$ \\
\hline PFR3 & 1240 & 3.00 & $8.56 ; 8.92 ; 8.56$ & $0.08 ; 0.08 ; 0.00$ & $2.40 ; 2.41 ; 2.42$ & $71.52 ; 67.04$ \\
\hline PFR4 & 1240 & 9.00 & $9.05 ; 9.42 ; 9.17$ & $0.08 ; 0.08 ; 0.00$ & $2.41 ; 2.41 ; 2.41$ & $70.83 ; 70.39$ \\
\hline PFR5 & 1143 & 6.00 & $2.26 ; 2.20 ; 2.26$ & $12.22 ; 12.68 ; 12.56$ & $1.94 ; 1.93 ; 1.93$ & $25.48 ; 25.66$ \\
\hline PFR6 & 1257 & 6.00 & $8.50 ; 8.68 ; 9.03$ & $0.08 ; 0.00 ; 0.00$ & $2.38 ; 2.39 ; 2.40$ & $65.31 ; 66.38$ \\
\hline PFR7 & 1200 & 1.76 & $7.81 ; 7.61 ; 7.73$ & $1.30 ; 1.54 ; 1.16$ & $2.34 ; 2.33 ; 2.35$ & $49.01 ; 51.86$ \\
\hline PFR8 & 1200 & 10.24 & $7.57 ; 6.86 ; 7.75$ & $1.53 ; 2.01 ; 1.22$ & $2.32 ; 2.29 ; 2.34$ & $44.07 ; 49.37$ \\
\hline PFR9 & 1200 & 6.00 & $8.33 ; 7.40 ; 8.42$ & $1.07 ; 1.98 ; 0.84$ & $2.36 ; 2.29 ; 2.37$ & $62.34 ; 57.03$ \\
\hline PFR10 & 1200 & 6.00 & $7.64 ; 7.68 ; 6.83$ & $1.77 ; 1.96 ; 2.88$ & $2.31 ; 2.30 ; 2.24$ & $54.46 ; 57.22$ \\
\hline PMCR1 & 1160 & 3.00 & $2.39 ; 2.78 ; 3.15$ & $8.19 ; 9.69 ; 9.36$ & $2.12 ; 2.02 ; 2.03$ & $31.05 ; 32.39$ \\
\hline PMCR2 & 1160 & 9.00 & $2.54 ; 2.83 ; 2.87$ & $10.03 ; 9.29 ; 9.78$ & $2.01 ; 2.03 ; 2.02$ & $28.60 ; 28.66$ \\
\hline PMCR3 & 1240 & 3.00 & $8.26 ; 8.33 ; 8.58$ & $0.23 ; 0.08 ; 0.00$ & $2.01 ; 1.94 ; 1.95$ & $70.99 ; 70.03$ \\
\hline PMCR4 & 1240 & 9.00 & $8.15 ; 8.17 ; 8.20$ & $0.16 ; 0.00 ; 0.01$ & $2.37 ; 2.36 ; 2.33$ & $68.62 ; 65.16$ \\
\hline PMCR5 & 1143 & 6.00 & $2.71 ; 1.69 ; 1.92$ & $10.15 ; 12.49 ; 12.00$ & $2.27 ; 2.28 ; 2.26$ & $24.35 ; 21.18$ \\
\hline PMCR6 & 1257 & 6.00 & $7.60 ; 7.71 ; 7.41$ & $0.00 ; 0.00 ; 0.00$ & $2.28 ; 2.31 ; 2.28$ & $61.35 ; 60.54$ \\
\hline PMCR7 & 1200 & 1.76 & $6.84 ; 6.90 ; 4.33$ & $2.51 ; 2.14 ; 3.10$ & $2.28 ; 2.31 ; 2.24$ & $48.68 ; 43.78$ \\
\hline PMCR8 & 1200 & 10.24 & $6.57 ; 6.85 ; 5.23$ & $2.24 ; 1.79 ; 3.55$ & $2.28 ; 2.31 ; 2.22$ & $40.22 ; 40.29$ \\
\hline PMCR9 & 1200 & 6.00 & $6.37 ; 7.02 ; 5.82$ & $2.30 ; 1.79 ; 2.88$ & $2.01 ; 1.94 ; 1.95$ & $39.58 ; 36.97$ \\
\hline PMCR10 & 1200 & 6.00 & $6.57 ; 7.01 ; 5.50$ & $2.18 ; 1.74 ; 3.59$ & $2.37 ; 2.36 ; 2.33$ & $46.39 ; 49.92$ \\
\hline
\end{tabular}

Table 5. Relevant statistics for the analysis of variance of the mathematical models that describe the variables LS, WA, AD and FS, for PFR and PMCR compositions.

\begin{tabular}{lccccc}
\hline Variable & Model & F-Test & F-Table & p-value & $\mathrm{R}^{2}$ \\
\hline $\mathrm{LS}_{\text {PFR }}$ & Quadratic & 462.39 & 3.35 & 0.00 & 0.97 \\
$\mathrm{LS}_{\text {PMCR }}$ & Quadratic & 143.49 & 3.35 & 0.00 & 0.91 \\
$\mathrm{WA}_{\text {PFR }}$ & Quadratic & 692.05 & 3.35 & 0.00 & 0.98 \\
$\mathrm{WA}_{\text {PMCR }}$ & Quadratic & 479.64 & 3.35 & 0.00 & 0.97 \\
$\mathrm{AD}_{\text {PFR }}$ & Quadratic & 430.00 & 3.35 & 0.00 & 0.97 \\
$\mathrm{AD}_{\text {PMCR }}$ & Quadratic & 185.00 & 3.35 & 0.00 & 0.92 \\
$\mathrm{FS}_{\text {PFR }}$ & Quadratic & 107.08 & 2.98 & 0.00 & 0.95 \\
$\mathrm{FS}_{\text {PMCR }}$ & Linear & 142.69 & 4.20 & 0.00 & 0.89 \\
\hline
\end{tabular}

Apparent density is a physical property that permits to evaluate the sintering status of the material and anticipates the microstructure of the final product ${ }^{3}$. In Fig. 5, it can be seen the great evolution of the apparent density values, which tend to systematically increase with firing temperature increasing. For both compositions, PFR and PMCR, the elevation of firing temperature from 1143 to $1240^{\circ} \mathrm{C}$ caused an increase of approximately $0.5 \mathrm{~g} / \mathrm{cm}^{3}$ in the apparent density of the material. Above $1240^{\circ} \mathrm{C}$, no more changes were observed in the values of the AD variable. Therefore, at this temperature, was reached the maximum densification $\left(\sim 2.4 \mathrm{~g} / \mathrm{cm}^{3}\right)$. This behavior is in good agreement with the observed linear shrinkage and water absorption values (Fig. 3 and Fig. 4).
From the careful observation of the Fig. 3 to 5, it is possible to notice that PFR compositions presented slightly better LS, WA and AD values for the firing temperatures of 1143,1160 and $1200^{\circ} \mathrm{C}$, in comparison to the PMCR compositions. The chemical composition of the milled coarse quartzite residue (Table 2) reveals appreciable contents of alkaline fluxes, which tends to accelerate the formation of a viscous liquid phase that fills the pores and promotes the densification of the material ${ }^{16}$. However, its particle size distribution disfavors this process. Coarser particles participate in chemical reactions with greater difficulty, due to the smaller specific surface area presented by them, which delays the formation of liquid phase ${ }^{26}$. 
(a) LSPFR
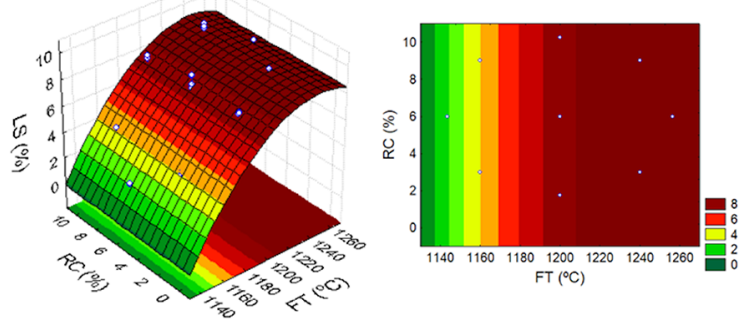

(b) LSPMCR
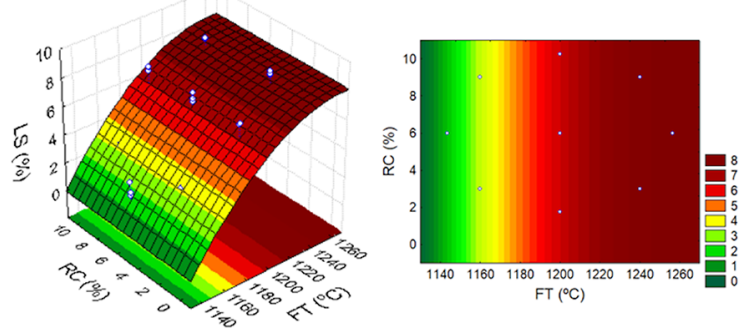

Figure 3. Response surface of the variable LS, for the compositions: (a) PFR and (b) PMCR.

\section{(a) WAPFR}
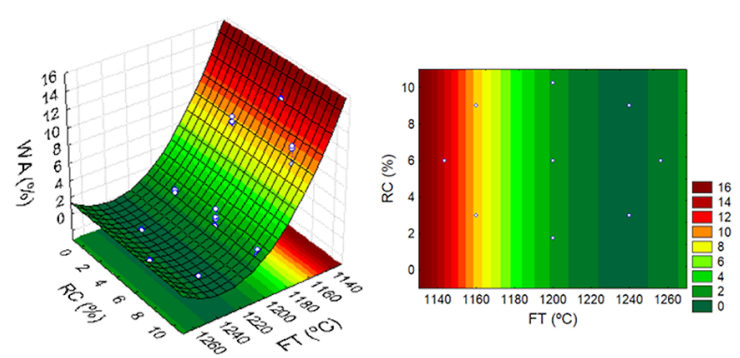

(b) WAPMCR
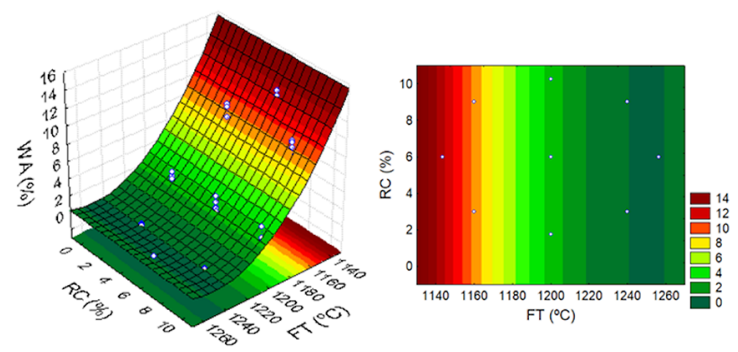

Figure 4. Response surface of the variable WA, for the compositions: (a) PFR and (b) PMCR.

In Fig. 6, it is verified that the flexural strength of both compositions, PFR and PMCR, increased approximately $50 \mathrm{MPa}$ with the elevation of the firing temperature from 1143 to $1257^{\circ} \mathrm{C}$. Studies carried out by Martín-Marquez et al. ${ }^{27}$ and Martín-Marquez et al. ${ }^{28}$ suggest that the mechanical strength of porcelain tiles is related to the decrease in porosity of the material, but also to the formation of mullite during sintering. Specifically, the higher the mullite content and the higher the interlocking of mullite needles, the higher is the flexural strength. Hence, the flexural strength of porcelain (a) ADPFR
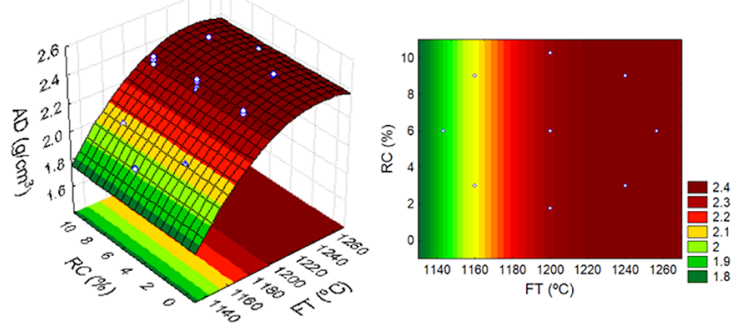

(b) ADPMCR
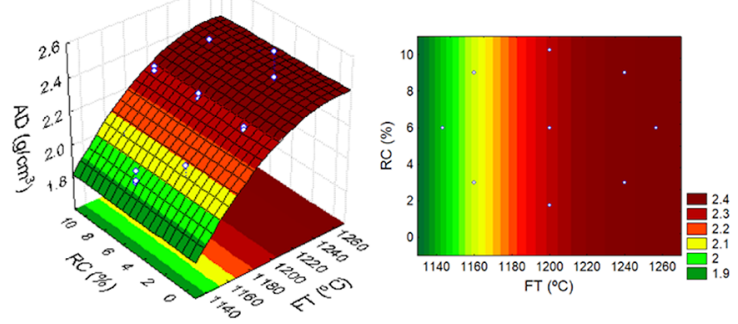

Figure 5. Response surface of the variable AD, for the compositions: (a) PFR and (b) PMCR.
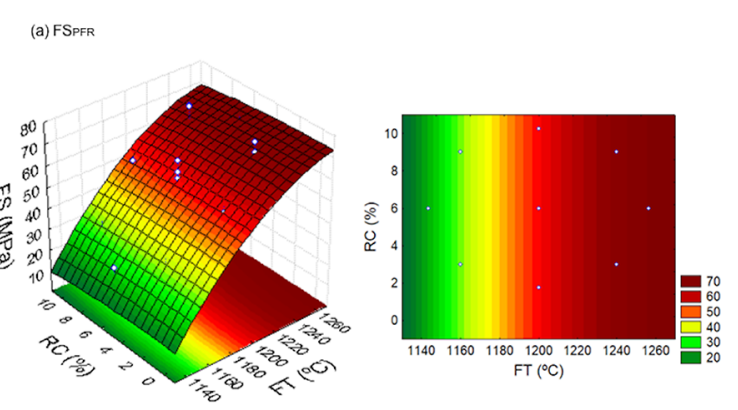

(b) FSPMCR
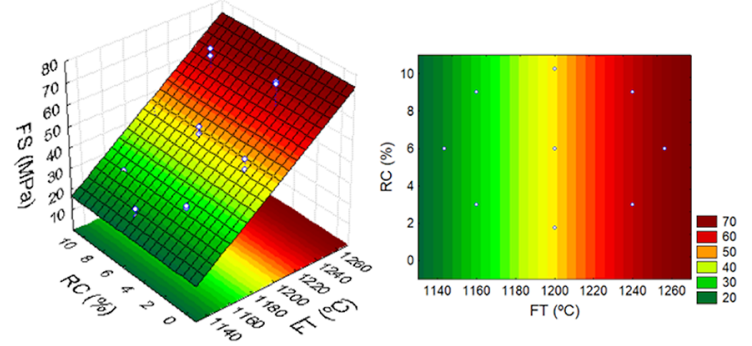

Figure 6. Response surface of the variable FS, for the compositions: (a) PFR and (b) PMCR.

tiles depends on the factors that affect the amount and size of mullite needles, like the firing temperature ${ }^{29}$. In addition, it can also be observed that the compositions with fine residue presented a slightly better mechanical performance in relation to those with milled coarse residue. Considering that the quartzite residues are composed mostly of quartz, the described behavior can be explained by Bragança et al. ${ }^{26}$. According to the researchers, the size of quartz particles is a factor of great influence on the mechanical strength of 
porcelain tiles. These particles should be dissolved into the liquid phase during sintering until a saturation limit is reached, so that the dissolution comes to end. However, the dissolution rate of quartz is size-dependent. Thus, it is expected that fine particles be dissolved at a higher rate and disappear faster than coarse particles, which often only suffer size reduction but not dissolve. Moreover, larger particles that do not completely dissolve in the liquid phase can act as defects in the microstructure of the porcelain tile and, in this way, favor its fracture when it is under tension. Besides that, the presence of residual quartz particles in the sintered ceramic pieces can be detrimental to their resistance due to the polymorphic transformation of $\alpha-\beta$ quartz during cooling ${ }^{29}$. The international standard ISO $13006^{25}$ establishes that porcelain tiles must present flexural strength equal to or greater than $35 \mathrm{MPa}$. This criteria was satisfied for

(a)
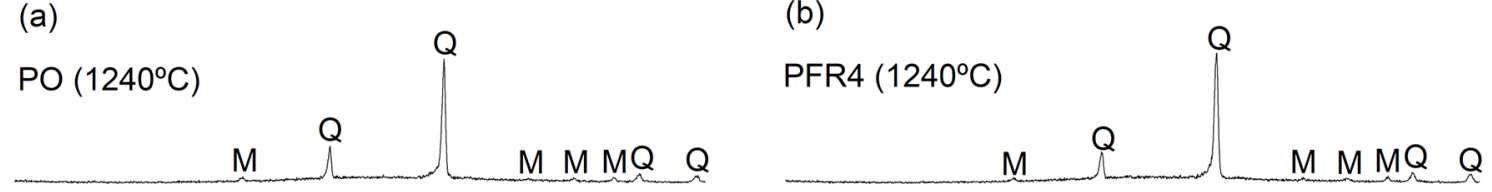

compositions with up to $10.24 \mathrm{wt} . \%$ of the quartzite residues, FR and MCR, sintered at temperatures higher than $1200^{\circ} \mathrm{C}$.

Fig. 7 shows the XRD spectra of the pieces produced from the pure ceramic mass (PO) and from the compositions with 9 wt.\% of fine residue (PFR2 and PFR4) and 9 wt.\% of milled coarse residue (PMCR2 and PMCR4), sintered at temperatures of 1160 and $1240^{\circ} \mathrm{C}$. For the pure porcelain tile sintered at $1160^{\circ} \mathrm{C}$, it is verified the presence of the following mineralogical phases: anorthite (JCPDS: 89-1462), mullite (JCPDS: 79-1275) and quartz (JCPDS: 46-1045), predominantly the two last. The presence of anorthite is due to the rapid and favorable chemical reaction that occurs between calcium oxide $(\mathrm{CaO})$, present in all raw materials, and the metakaolinite resulting from the dehydroxylation of kaolinite ${ }^{30}$. However, when the firing temperature was raised to $1240^{\circ} \mathrm{C}$, this crystalline phase disappeared completely,
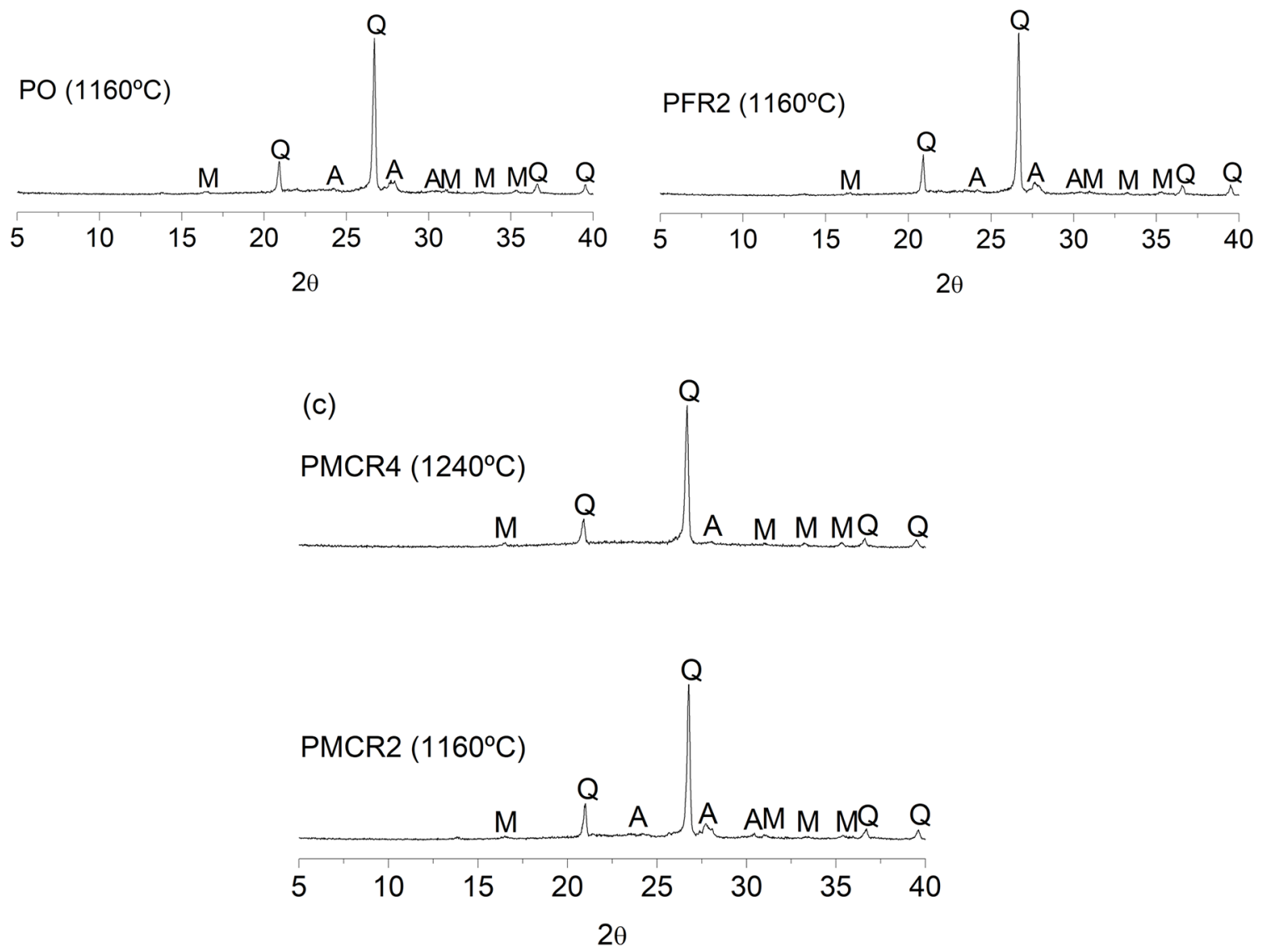

Figure 7. XRD spectra of pieces produced from: (a) ceramic mass for porcelain tile (PO); (b) composition with 9 wt.\% of fine quartzite residue (PFR2, PFR4); (c) composition with $9 \mathrm{wt} . \%$ of milled coarse quartzite residue (PMCR2, PMCR4); sintered at 1160 and $1240^{\circ} \mathrm{C}$. A - Anorthite; M - Mullite; Q - Quartz. 
remaining the mullite and the quartz. The persistent presence of quartz, even at higher temperatures, is the result of its slow dissolution kinetics ${ }^{31}$.

It is observed that the XRD spectra of the pieces PFR2 and PFR4 exhibit peaks of the same crystalline phases which were presented by the pure porcelain tile, sintered at the temperatures of 1160 and $1240^{\circ} \mathrm{C}$, respectively. There is also great similarity in peaks intensity. It means that the incorporation of fine quartzite residue in the ceramic mass did not affect the mineralogical profile of the sintered material. In relation to the composition with milled coarse residue, it is verified that PMCR2 presents the same mineralogical phases as pure porcelain tile sintered at $1160^{\circ} \mathrm{C}$. However, the anorthite phase does not completely disappear when the material is sintered at $1240^{\circ} \mathrm{C}$ (PMCR4). In this case, the presence of anorthite at higher temperatures is due to the chemical composition of the coarse quartzite residue, which presents a higher $\mathrm{CaO}$ content when compared to the fine residue, resulting in a higher production of this crystalline phase and, consequently, in a greater difficulty in dissolving it completely. In addition, it can be noticed that the quartz peaks presented by the piece PMCR4 are more intense than those presented by the PRF4 and by the pure porcelain sintered at $1240^{\circ} \mathrm{C}$. This behavior is attributed to the dissolution kinetics of coarser quartz particles, which is even slower than for finer particles.

Fig. 8 shows SEM micrographs of the fracture surfaces of pieces produced from the pure porcelain ceramic mass (PO) and from the compositions with $9 \mathrm{wt} . \%$ of fine quartzite residue (PFR2 and PFR4) and 9 wt.\% of milled coarse quartzite (a)

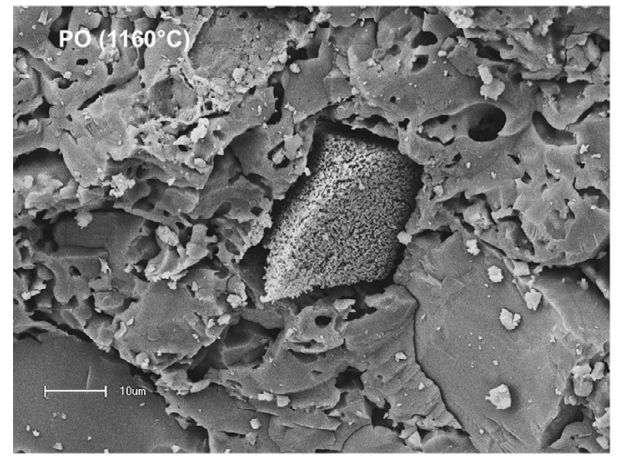

(b)

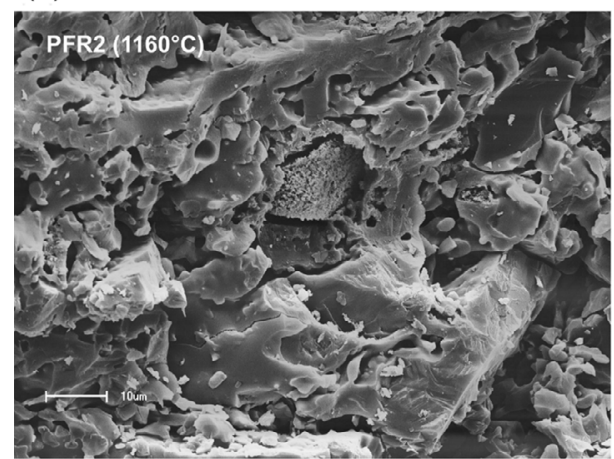

(c)

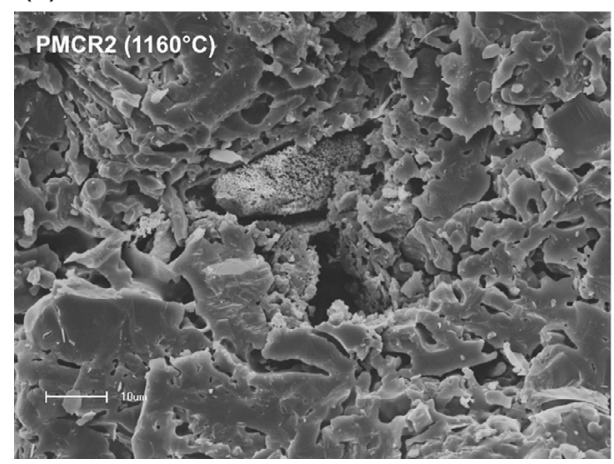

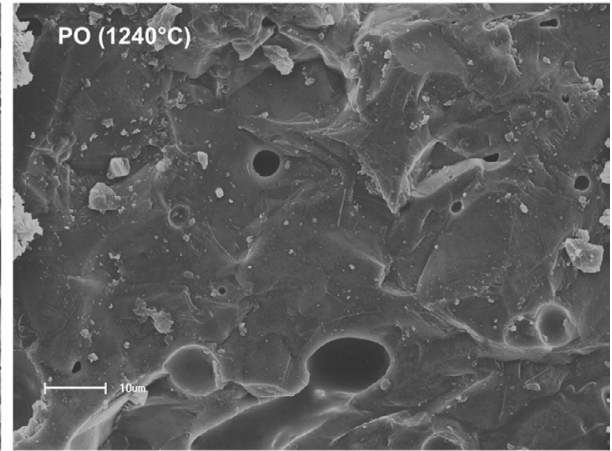
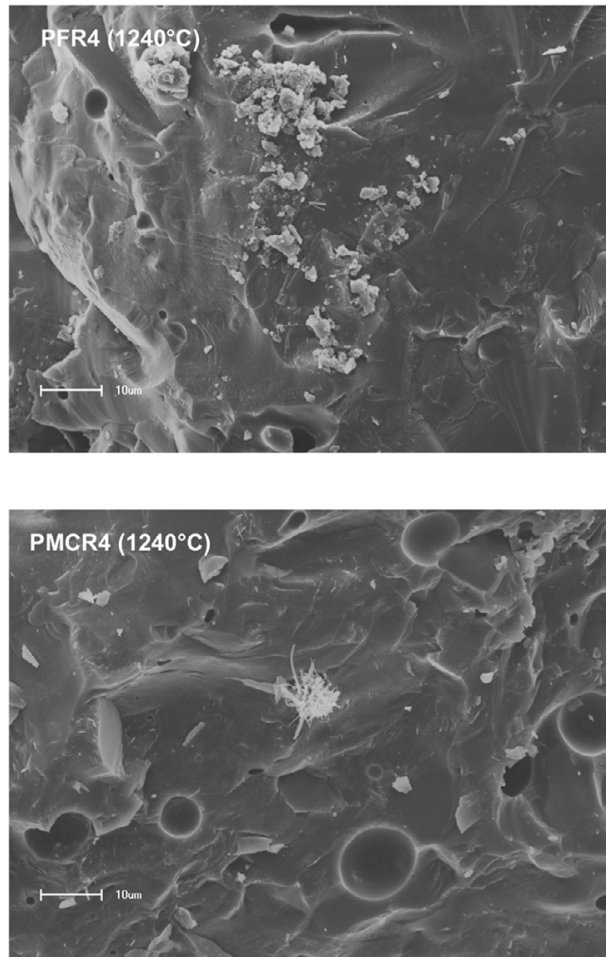

Figure 8. SEM micrographs of the fracture surface of pieces produced from: (a) ceramic mass for porcelain tile (PO); (b) composition with 9 wt.\% of fine quartzite residue (PFR2, PFR4); (c) composition with 9 wt.\% of milled coarse quartzite residue (PMCR2, PMCR4); sintered at 1160 and $1240^{\circ} \mathrm{C}$. 
residue (PMCR2 and PMCR4), sintered at temperatures of 1160 and $1240^{\circ} \mathrm{C}$. All the ceramic pieces that were sintered at $1160^{\circ} \mathrm{C}$ have microstructures very similar to each other, totally irregular and highly porous, containing cracks and particles of different sizes and shapes. It is observed the existence of some agglomerates that stand out in the middle of the matrix due to its rougher aspect. They can be associated with the anorthite phase, previously revealed by XRD analyzes. Other researchers found structures very similar to these, present in porcelain stoneware bodies sintered at $1100^{\circ} \mathrm{C}^{28}$. The pieces sintered at $1240^{\circ} \mathrm{C}$ present microstructures with high degree of densification, containing some closed pores, which are characterized by the spherical shape, large and isolated ${ }^{32}$. The great similarity observed between the microstructures of pure porcelain tile and of compositions with quartzite residues, FR and MCR, indicates that the incorporation of these two types of residue did not affect the morphological profile of the material when it was submitted to different firing temperatures.

\section{Conclusions}

The quartzite residues, FR and MCR, present adequate chemical and mineralogical properties so that they can be incorporated in a ceramic mass for porcelain tile production. The incorporation of both residues, up to $10.24 \mathrm{wt.} \%$, did not cause significant changes in the particle size distribution and in the thermal profile of the ceramic mass.

The use of central composite design to evaluate the effects of firing temperature and residue content on the physical-mechanical properties of the material, was adequate for ceramic mass for porcelain tile, and it was possible to obtain statistically significant mathematical models, which correlate the factors FT and RC with the dependent variables LS, WA, AD and FS.

The firing temperature had statistically significant effect on all the investigated response variables, so that the elevation of its levels contributed to the improvement of the studied properties: linear shrinkage, water absorption, apparent density and 3-point flexural strength. On the other hand, the residue content, in the studied range, did not generate significant effects. It means that the incorporation of quartzite residues, with different particle sizes, did not affect the physical-mechanical properties of the material, making possible its use as a non-plastic raw material in porcelain tile production.

The compositions with fine quartzite residue presented a slightly better performance than those with milled coarse residue.

Considering that the international standard ISO $13006^{16}$ classifies porcelain tiles as ceramic tiles that present water absorption equal to or less than $0.5 \%$ and flexural strength equal to or greater than $35 \mathrm{MPa}$, fall into this category the compositions with up to $10.24 \mathrm{wt} . \%$ of fine and milled coarse quartzite residues, which were sintered at $1240^{\circ} \mathrm{C}$ and $1257^{\circ} \mathrm{C}$.

The experimental results showed that the incorporation of residues from the extraction and processing of quartzite in ceramic mass for porcelain tile production presents itself as an environmental and technological solution.

\section{Acknowledgments}

Authors acknowledge financial support received from CAPES and CNPq (proc. 447881/2014-0 and 308912/2016-0), Brazil.

\section{References}

1. Raupp-Pereira F, Hotza D, Segadães AM, Labrincha JA. Ceramic formulations prepared with industrial wastes and natural sub-products. Ceramics International. 2006;32(2):173179.

2. Silva MA, Paes HF Jr, Holanda JNF. Reuse of ornamental rock-cutting waste in aluminous porcelain. Journal of Environmental Management. 2011;92(3):936-940.

3. Torres P, Manjate RS, Quaresma S, Fernandes HR, Ferreira JMF. Development of ceramic floor tile compositions based on quartzite and granite sludges. Journal of the European Ceramic Society. 2007;27(16):4649-4655.

4. Junkes JA, Prates PB, Hotza D, Segadães AM. Combining mineral and clay-based wastes to produce porcelain-like ceramics: An exploratory study. Applied Clay Science. 2012;69:50-57.

5. Pinheiro BCA, Holanda JNF. Obtainment of porcelain floor tiles added with petroleum oily sludge. Ceramics International. 2013;39(1):57-63.

6. Carreiro MEA, Santos RC, Silva VJ, Lira HL, Neves GA, Menezes RR, et al. Residue of quartzite - alternative raw material for use in structural ceramics. Cerâmica. 2016;62(362):170-178.

7. de Medeiros PSS, Santana LNL, Silva VJ, Neves GA, Lira HL. Evaluation of the Potential of Using Quartzite Residue in Mass for the Production of Sanitary Ware. Materials Science Forum. 2016;869:181-185.

8. Barros SVA, Marciano JEA, Ferreira HC, Menezes RR, Neves GA. Addition of quartzite residues on mortars: Analysis of the alkali aggregate reaction and the mechanical behavior. Construction and Building Materials. 2016;118:344-351.

9. Montgomery DC. Design and Analysis of Experiments. New York: John Wiley \& Sons; 1991.

10. Naik PK, Reddy PSR, Misra VN. Optimization of coal flotation using statistical technique. Fuel Processing Technology. 2004;85(13):1473-1485

11. Lamarra J, Rivero S, Pinotti A. Design of chitosan-based nanoparticles functionalized with gallic acid. Materials Science and Engineering: C. Materials for Biological Applications. 2016;67:717-726. 
12. Jensen DR. Efficiency comparisons of central composite designs. Journal of Statistical Computation and Simulation. 1995;52(2):177-183.

13. Mehrabani JV, Noaparast M, Mousavi SM, Dehghan R, Ghorbani A. Process optimization and modelling of sphalerite flotation from a low-grade $\mathrm{Zn}$-Pb ore using response surface methodology. Separation and Purification Technology. 2010;72(3):242-249.

14. Aslan N. Application of response surface methodology and central composite rotatable design for modeling the influence of some operating variables of a Multi-Gravity Separator for coal cleaning. Fuel. 2007;86(5-6):769-776.

15. Torres P, Fernandes HR, Olhero S, Ferreira JMF. Incorporation of wastes from granite rock cutting and polishing industries to produce roof tiles. Journal of the European Ceramic Society. 2009;29(1):23-30.

16. Moreira JMS, Manhães JPVT, Holanda JNF. Processing of red ceramic using ornamental rock powder waste. Journal of Materials Processing Technology. 2008;196(1-3):88-93.

17. Taguchi SP, Santos JC, Gomes TM, Cunha NA. Evaluation of technological properties of red ceramics incorporated with dimension stone waste from diamond wire loom. Cerâmica. 2014;60(354):291-296

18. da Silva VJ, da Silva MF, Gonçalves WP, de Menezes RR, Neves GA, Lira HL, et al. Porous mullite blocks with compositions containing kaolin and alumina waste. Ceramics International. 2016;42(14):15471-15478.

19. Ke S, Wang Y, Pan Z, Ning C, Zheng S. Recycling of polished tile waste as a main raw material in porcelain tiles. Journal of Cleaner Production. 2016;115:238-244.

20. Lerdprom W, Chinnam RK, Jayaseelan DD, Lee WE. Porcelain production by direct sintering. Journal of the European Ceramic Society. 2016;36(16):4319-4325.

21. Gonçalves WP, Silva VJ, Menezes RR, Neves GA, Lira HL, Santana LNL. Microstructural, physical and mechanical behavior of pastes containing clays and alumina waste. Applied Clay Science. 2017;137:259-265.
22. Campos LFA, Menezes RR, Lisboa D, Santana LNL, Neves GA, Ferreira HC. Experimental design to maximize the waste content in ceramic bricks and tiles. Cerâmica. 2007;53(328):373-380.

23. Amorós JL, Orts MJ, García-Ten J, Gozalbo A, Sánchez E. Effect of the green porous texture on porcelain tile properties. Journal of the European Ceramic Society. 2007;27(5):22952301.

24. Gültekin EE, Topates G, Kurama S. The effects of sintering temperature on phase and pore evolution in porcelain tiles. Ceramics International. 2017;43(14):11511-11515.

25. International Organization for Standardization (ISO). ISO 13006 - Ceramic tiles - Definitions, classification, characteristics and marking. Geneva: ISO; 1998.

26. Bragança SR, Bergmann CP. Production of bone porcelain and characterization of its technical properties. Cerâmica. 2006;52(322):205-212.

27. Martín-Márquez J, Rincón JM, Romero M. Effect of microstructure on mechanical properties of porcelain stoneware. Journal of the European Ceramic Society. 2010;30(15):3063-3069.

28. Martín-Márquez J, Rincón JM, Romero M. Mullite development on firing in porcelain stoneware bodies. Journal of the European Ceramic Society. 2010;30(7):1599-1607.

29. Stathis G, Ekonomakou A, Stournaras CJ, Ftikos C. Effect of firing conditions, filler grain size and quartz content on bending strength and physical properties of sanitaryware porcelain. Journal of the European Ceramic Society. 2004;24(8):2357-2366.

30. Bragança SR, Bergmann CP, Hübner H. Effect of quartz particle size on the strength of triaxial porcelain. Journal of the European Ceramic Society. 2006;26(16):3761-3768.

31. Santana LNL, Gomes J, Menezes RR, Neves GA, Lira HL, Segadães AM. Microstructure development in clays upon heat treatment: Kinetics and equilibrium. Applied Clay Science. 2017;135:325-332.

32. Martín-Márquez J, Rincón JM, Romero M. Effect of firing temperature on sintering of porcelain stoneware tiles. Ceramics International. 2008;34(8):1867-1873. 